\title{
Pasteurellaceae members with similar morphological patterns associated with respiratory manifestations in ducks
}

\author{
Samah Eid ${ }^{1}$, Sherif Marouf ${ }^{2}$, Hefny Y. Hefny ${ }^{3}$ and Nayera M. Al-Atfeehy ${ }^{1}$
}

1. Department of Bacteriology, Reference Laboratory for Veterinary Quality Control on Poultry Production, Animal Health Research Institute, Agricultural Research Centre, Nadi El-Seid St., P.O. Box 246, Dokki, Giza 12618, Egypt; 2. Department of Microbiology, Faculty of Veterinary Medicine, Cairo University, Giza, Egypt; 3. Department of Poultry Diseases, Zagazig Provincial Laboratory, Animal Health Research Institute, Agricultural Research Centre, Sharkia, Egypt. Corresponding author: Samah Eid, e-mail: samaheid@ymail.com

Co-authors: SM: drsherif_marouf@yahoo.com, HYH: youssefhefny@yahoo.com, NMA: hanya_noour@yahoo.com Received: 30-08-2019, Accepted: 25-11-2019, Published online: 26-12-2019

doi: www.doi.org/10.14202/vetworld.2019.2061-2069 How to cite this article: Eid S, Marouf S, Hefny HY, Al-Atfeehy NM (2019) Pasteurellaceae members with similar morphological patterns associated with respiratory manifestations in ducks, Veterinary World, 12(12): 2061-2069.

\begin{abstract}
Aim: A total of 112 freshly dead ducks aged from 2 to 20 weeks old with a history of respiratory manifestations were investigated for the implication of Pasteurellaceae family members.

Materials and Methods: Isolation and identification to the family level were conducted by conventional bacteriological methods, including microscopic examination and biochemical characterization. Identification to the species level was conducted by polymerase chain reaction (PCR) and analytical profile index (API) 20E kits.

Results: Conventional bacteriological isolation and biochemical characterization revealed the infection of 16/112 examined birds with a prevalence rate of $14.3 \%$. PCR confirmed the detection of Pasteurellaceae family conserved genes RpoB and Bootz in 16/16 (100\%) isolates. PCR was also used for genus and species identification of the isolated Pasteurellaceae members; the results revealed that 5/16 (31.3\%) of isolates were Gallibacterium anatis and 2/16 of isolates (12.5\%) were Pasteurella multocida. Riemerella anatipestifer, Mannheimia haemolytica, and Avibacterium paragallinarum were not detected by PCR. Biotyping by API 20E successfully identified 5/16 (31.3\%) isolates that could not be typed by PCR and confirmed their belonging to Pasteurella pneumotropica. Neither the available PCR primer sets nor API 20E succeeded for species identification of 4/16 (25\%) isolates. Antibiotic susceptibility profiling of isolates revealed that $16 / 16(100 \%)$ of isolates demonstrated multidrug resistance (MDR) phenotypes. Moreover, 16/16 (100\%) of isolates demonstrated a phenotypic resistance pattern to neomycin.

Conclusion: Combined genotypic, phenotypic, biotyping, and virulence characterizations are required for laboratory identification of pathogenic Pasteurellaceae. Moreover, P. multocida was not the prevailed member implicated in respiratory problems in ducks as P. pneumotropica, G. anatis, and unidentified strains were involved with higher prevalence. Chloramphenicol and ampicillin demonstrated the highest in vitro effects on the studied Pasteurellaceae. Furthermore, the prevalence of multidrug-resistant isolates signified the demand to implement targeted surveillance in the ducks' production sector, and MDR survey in poultry sectors in Egypt to apply effective control measures.
\end{abstract}

Keywords: ducks, Gallibacterium anatis, Mannheimia haemolytica, Pasteurella multocida, Riemerella anatipestifer.

\section{Introduction}

Rearing ducks are popular in Egypt at households and intensive commercial production systems as well. The popularity of ducks' production in Egypt is encouraged by the fact that ducks are better adapted than chickens for environmental conditions, require less care, and are more resistant to diseases in addition to being of high and palatable meat and eggs [1]. Analysis of agricultural data demonstrated that ducks' meat importation international record increased from 81 thousand tons to 187 thousand tons $(+130 \%)$ in the past two decades as consumers mostly prefer meat and

Copyright: Eid, et al. Open Access. This article is distributed under the terms of the Creative Commons Attribution 4.0 International License (http://creativecommons.org/licenses/by/4.0/), which permits unrestricted use, distribution, and reproduction in any medium, provided you give appropriate credit to the original author(s) and the source, provide a link to the Creative Commons license, and indicate if changes were made. The Creative Commons Public Domain Dedication waiver (http://creativecommons.org/ publicdomain/zero/1.0/) applies to the data made available in this article, unless otherwise stated. eggs of ducks and geese not only because of their taste but also for their high nutritional value and the fact that they contain optimum quantity of essential amino acids and fatty acids [2].

Although most Pasteurellaceae family members are considered commensals, some cause a variety of diseases in humans and animals, in this regard, pasteurellosis caused by Pasteurella multocida is proven to be contagious and endemic disease that causes high morbidity and mortality in domestic and wild birds. Furthermore, pasteurellosis is considered one of the major causes associated with high mortality in ducks [3].

Taxonomy of Pasteurellaceae is not adequately settled and is still under revision, in this instance taxonomy studies involved mainly phenotypic characterization and few scientific works have studied taxonomy to the genotypic level [4]. Since 1995, Pasteurellaceae family has been expanded from three to 13 genera through the use of new genetic-based 
classification and identification technologies, for example, genus Gallibacterium [5]. Recently, the three genera Haemophilus, Actinobacillus, and Pasteurella which originally formed the family, have been joined by new genera [6]. Currently, the family Pasteurellaceae comprises 57 named bacterial species that have been isolated from man and animals. The use of large and specific set of biochemical tests to identify and differentiate natural taxa of Pasteurella and related groups of organisms was described in several studies [7,8].

With the exception of $P$. multocida, limited studies are available with regard to the investigation of ducks' infection with different genera and species of Pasteurellaceae family. Thus, fowl cholera caused by $P$. multocida remains one of the main problems of poultry worldwide and represents serious threats for ducks in Egypt [9,10].

For the past decade, antimicrobial resistance has become a problem of concern in human and veterinary medicines as being implicated in the failure of treatments' protocols. Therefore, the proper determination of the resistance patterns represents a prerequisite for adapting successful control measures.

This study aimed to investigate the implication of Pasteurellaceae members as causative agents of respiratory diseases in ducks by applying comprehensive laboratory diagnostic tools using bacteriological, biochemical assays, and molecular approaches for differentiation between the phenotypic Pasteurellaceae variants to the genus and species levels. The study also aimed to investigate the antimicrobial resistance attributes of isolates.

\section{Materials and Methods}

\section{Ethical approval}

Albino mice used in the pathogenicity test were dealt with, according to OIE, Terrestrial Animal Health Code, 2018 [11].

\section{Sample collection}

A total of 112 freshly dead ducks (Muscovy and Mallard) aged from 2 to 20 weeks old with a history of respiratory manifestations, high morbidity, and high mortality rates were transported under aseptic condition in iceboxes within maximum $24 \mathrm{~h}$ from commercial farms located at Hefna town, Belbes district, Sharkia Governorate, Egypt to Animal Health Research Provincial Laboratory in Zagazig city for postmortem examination and sampling from internal organs (liver, lung, heart, and spleen), freshly dead carcasses were kept in maintained refrigeration temperature at $5^{\circ} \mathrm{C} \pm 2^{\circ} \mathrm{C}$ during the period elapsed from farm investigation till delivered to the laboratory. The study was applied during winter season 2018-2019.

\section{Postmortem examination}

The carcasses that demonstrated different degrees of congestion in internal organs (liver, lungs, and spleen) with multiple, small necrotic foci and petechial hemorrhage on the coronary fat, thoracic air sacs, trachea, endocardium, and intestines were considered suspected for Pasteurellaceae infection; subsequently, internal organs (liver, lung, heart, and spleen) were collected under aseptic condition and transferred in iceboxes to reference laboratory for quality control on poultry production (RLQP), Dokki for laboratory diagnosis.

Isolation, phenotypic, and biochemical identification

Samples were inoculated in brain heart infusion (BHI) broth, incubated at $37^{\circ} \mathrm{C}$ for $24 \mathrm{~h}$. Loopful from broth culture was streaked onto blood agar plate $(5 \%$ sheep blood), MacConkey agar plate and incubated at $37^{\circ} \mathrm{C}$ for $24 \mathrm{~h}$.

Small circular convex glistening dewdrop like colonies, with or without hemolysis on 5\% sheep blood agar plate, were considered suspected colonies for Pasteurellaceae family.

The isolated pure culture was smeared, stained with Gram and Leishman's stains for microscopic examination and identification of characteristic bipolar isolates. Cultures were evaluated for oxidase activity, tryptophanase activity by indole test, catalase activity, urease activity, citrate utilization test, and $\mathrm{H} 2 \mathrm{~S}$ production, according to Florence et al. [12]. Isolates were also tested for fermentation of carbohydrates (mannitol, trehalose, sorbitol, glucose, mannose, fructose, xylose, arabinose, lactose, galactose, and dulcitol).

The isolates were identified on the basis of phenotypic, cultural and biochemical characteristics, combined with microscopic examination and morphological characteristics by Gram staining as Gramnegative coccobacilli, bipolarity by Leishman's stain, according to Bisgaard et al. [13].

\section{Pathogenicity in mice}

A loopful from each of 16 isolates was propagated in BHI broth for $18 \mathrm{~h}$ at $37^{\circ} \mathrm{C}, 0.1 \mathrm{ml}$ from each broth culture was injected subcutaneously into two albino mice (Female BALB/c mice at 6-10 weeks of age), and two mice were inoculated with $0.1 \mathrm{ml}$ of sterile BHI broth as negative control, according to Ramdani et al. [14]. The challenged 32 and the two control mice were observed for $48 \mathrm{~h}$; mortality was recorded. Heart blood smears and impression smears of spleen, liver, and lung were applied from dead mice, stained with Leishman's stain, and streaked on $5 \%$ sheep blood agar for reisolation.

\section{Antimicrobial susceptibility profiles}

Antimicrobial susceptibility profiles of isolates were studied by disk diffusion method against 11 antimicrobial agents of the most commonly used in the domestic field for the treatment of respiratory manifestations in ducks and that belong to 8 antimicrobial groups as follows: Spectinomycin (SH-100 $\mu \mathrm{g})$, nalidixic acid (NA-30 $\mu \mathrm{g}$ ), penicillin (P-10 $\mu \mathrm{g})$, cefotaxime $(\mathrm{CTX}-30 \mu \mathrm{g})$, trimethoprim (TR-5 $\mu \mathrm{g}$ ), ampicillin (AMP-10 $\mu \mathrm{g}$ ), oxytetracycline (OT-30 $\mu \mathrm{g}$ ), chloramphenicol (C-30 $\mu \mathrm{g})$, nitrofurantoin (F-300 $\mu \mathrm{g}$ ), 
neomycin $(\mathrm{N}-30 \mu \mathrm{g})$, and levofloxacin (LEV-5 $\mu \mathrm{g})$, and the test was performed and interpreted, according to CLSI-M45 A2, [15].

Confirmation and species identification of isolates by polymerase chain reaction (PCR)

\section{DNA extraction}

Genomic DNA extract was obtained using (Gene JET Genomic DNA purification Kit Thermo scientific). DNA concentration was determined by a spectrophotometer at $260 / 230 \mathrm{~nm}$. The used primers, PCR conditions, and thermal profiles are listed in Table-1 [4,16-22].

\section{PCR amplification}

PCR reaction was performed in a gradient thermal cycler (1000 S Thermal cycler Bio-RAD USA). The reaction mixture with a total volume of $50 \mu 1$; was consisted of $25 \mu \mathrm{l}$ dream green PCR Mix (Dream Taq Green PCR Master Mix (2×) Thermo Scientific Company- cat. No.K1080, USA.), $3 \mu 1$ target DNA, $1 \mu 1$ of each primers with a concentration of $10 \mathrm{p}$ mole/ $\mu \mathrm{l}$, the mixture was completed to $50 \mu 1$ with PCR water. Positive control strain: Standard strain confirmed and provided by ISO 17025 Biotechnology Department AHRI, Dokki Giza, Egypt, was used, negative control: Escherichia coli reference strain: NCTC 12241/ATCC 2522 was used as a negative control.

\section{Analysis of PCR products}

PCR products were separated by electrophoresis on $1 \%$ agarose gel (Applichem, Germany, $\mathrm{GmbH}$ ) in $1 \times \mathrm{TBE}$ buffer at room temperature using gradients of $5 \mathrm{~V} / \mathrm{cm}$. For gel analysis, $15 \mu \mathrm{l}$ of products were loaded in each gel slot. Gel pilot 100 bp plus ladder (Qiagen, Germany, GmbH) was used to determine the fragment size. The gel was photographed by a gel documentation system (Alpha Innotech, Biometra).

\section{Results}

Prevalence rate of Pasteurellaceae family

Results of isolation and biochemical characterization revealed that Pasteurellaceae family members were isolated from 16 out of 112 examined birds with a prevalence rate of $14.3 \%$, a higher prevalence rate of $8 / 28(28.6 \%)$ was detected in the age group of $<6$ weeks old, Table- 2 . The results of isolation also demonstrated that the prevalence rate was higher in Muscovy breed (6 out of 39 examined ducks) compared with Mallard breed (10 out of examined 73) with prevalence rates of $15.4 \%$ and $13.7 \%$, respectively.

\section{Pathogenicity test in albino mice}

The study of pathogenicity test in challenged albino mice (Female BALB/c mice at 6-10 weeks of age) for the 16 Pasteurellaceae isolates resulted in $100 \%$ mortality of mice within $48 \mathrm{~h}$, whereas, no mortality was recorded in the control mice. Smears of heart blood, spleen, liver, and lung from dead mice revealed the identification of characteristic bipolar microorganisms with Leishman's stain.

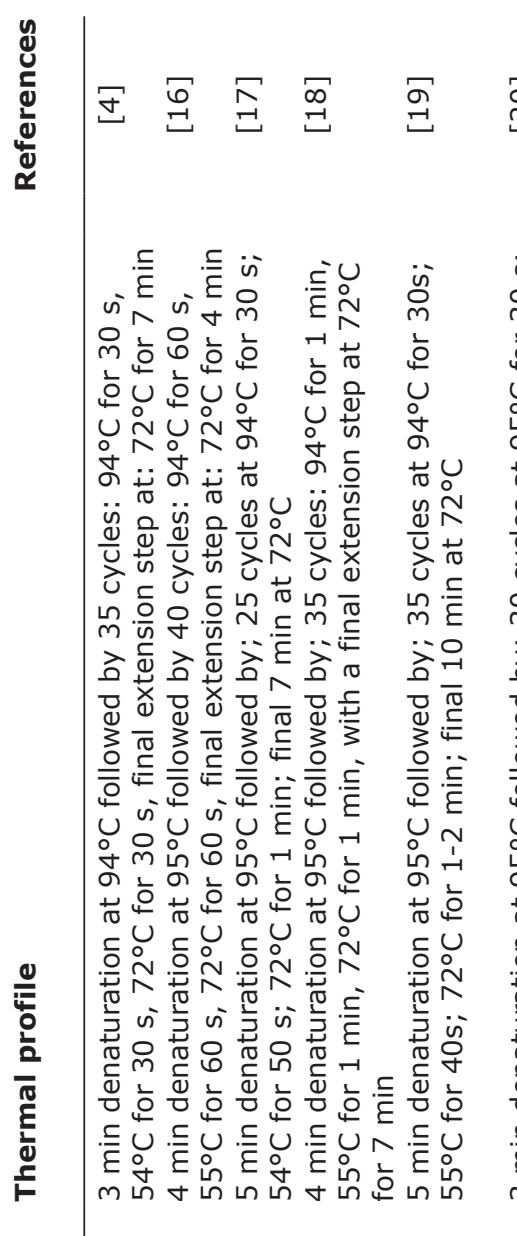

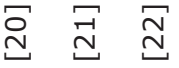

is .

¿ें

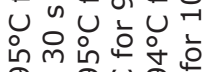

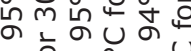

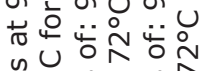

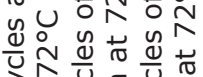

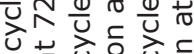

등ำ

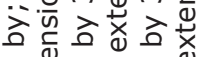

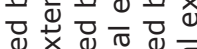

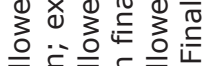

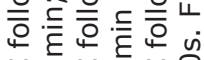

U⿺乚一匕

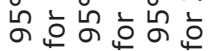

范范范

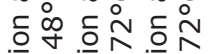

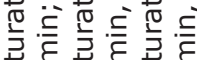

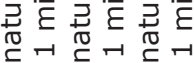

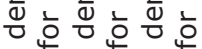

ह气

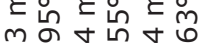
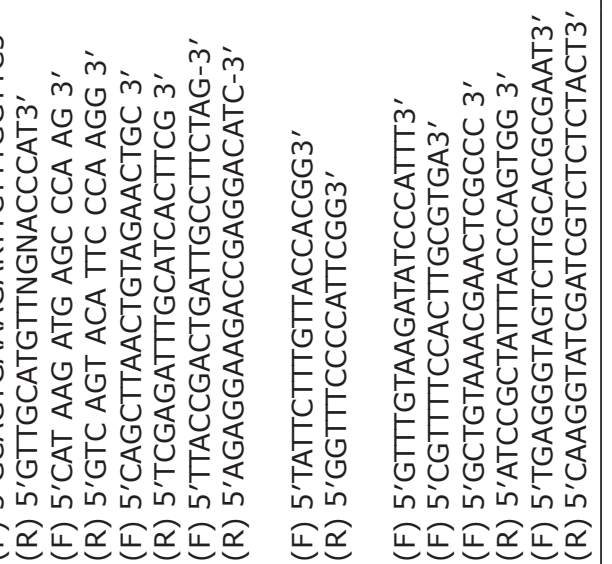

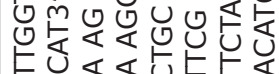

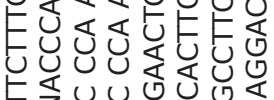

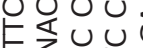

筞 0

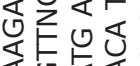

这这定

它悹是安

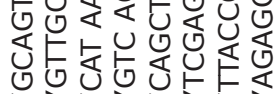

in in in in in in in in

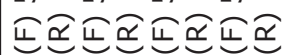

î̀

过

过

芫

(5)

\section{m}

ํㅜㅁ

$\underset{ }{N}$

음 
Table-2: Prevalence rate of Pasteurellaceae family members with regard to birds' age group.

\begin{tabular}{lccc}
\hline Age group & \multicolumn{2}{c}{ Number of birds } & $\begin{array}{c}\text { Prevalence } \\
\text { rate (\%) }\end{array}$ \\
\cline { 2 - 3 } $\begin{array}{c}\text { Examined } \\
\text { birds }\end{array}$ & $\begin{array}{c}\text { Infected } \\
\text { birds }\end{array}$ & \\
\hline$<6$ weeks old & 28 & 8 & $28.6^{*}$ \\
$6-12$ weeks old & 48 & 5 & $10.4^{*}$ \\
$>12$ weeks old & 36 & 3 & $8.3^{*}$ \\
Total & 112 & 16 & $14.3^{* *}$ \\
\hline
\end{tabular}

*The prevalence rate was calculated based on the number of examined birds in each age group, **The prevalence rate was calculated based on the total number of examined birds

Antimicrobial susceptibility profiling of isolates was tested against 11 of the most field used antimicrobial agents that belong to eight antimicrobial groups, the results revealed that $16 / 16(100 \%)$ of isolates demonstrated phenotypic resistance patterns against neomycin, while none of the isolates demonstrated resistance to nitrofurantoin. Moreover, 14/16 (87.5\%) of isolates demonstrated phenotypic resistance to spectinomycin, penicillin $\mathrm{G}$, and 13/16 (81.3\%) of isolates demonstrated phenotypic resistance to oxytetracycline, and 12/16 (75\%) of isolates demonstrated resistance to nalidixic acid, 9/16 (56.3\%) to levofloxacin. Moreover, resistance rates to cefotaxime, trimethoprim, ampicillin, and chloramphenicol were $7 / 16(43.8 \%), 6 / 16(37.5 \%), 4 / 16(25 \%)$, and $2 / 16(12.5 \%)$, respectively. The results also revealed that $16 / 16(100 \%)$ of isolates demonstrated multidrug resistance (MDR) phenotypes to antimicrobial agents that belong to three and more antimicrobial categories as interpreted by CLSI-M45 A2, [15]. The results also revealed that $8 / 16(50 \%), 3 / 16(18.8 \%)$, and 2/16 (33.3\%) of isolates demonstrated MDR to antimicrobial agents that belong to 5, 4, and 6 antimicrobial groups, respectively, Table-3.

\section{PCR for confirmation and species identification}

PCR confirmed that the 16 isolates belonged to family Pasteurellaceae by the detection of the specific conserved genes, Pas Rpob-L gene, and Bootz gene, Figures-1a and b, 2a and b, respectively. PCR testing for the presence of $K M T$ gene also confirmed that $2 / 16(12.5 \%)$ of isolates belonged to P. multocida. PCR testing for the detection of 16S RNA and 23S RNA genes of Gallibacterium anatis confirmed the positivity of 5/16 (31.3\%) of isolates. However, PCR failed to detect Rpt2 gene specific for Mannheimia haemolytica, PCR also failed to detect 669 A gene and 16S rRNA gene specific for Riemerella anatipestifer, furthermore, PCR failed to detect $H P G-2$ gene specific for Avibacterium paragallinarum, respectively.

\section{Biotyping of isolates by analytical profile index (API) 20E kit}

API 20E test was applied for biotyping and identification of the nine isolates that were not identified by the available used PCR primer sets, the result revealed that $5 / 16(31.3 \%)$ of isolates were identified

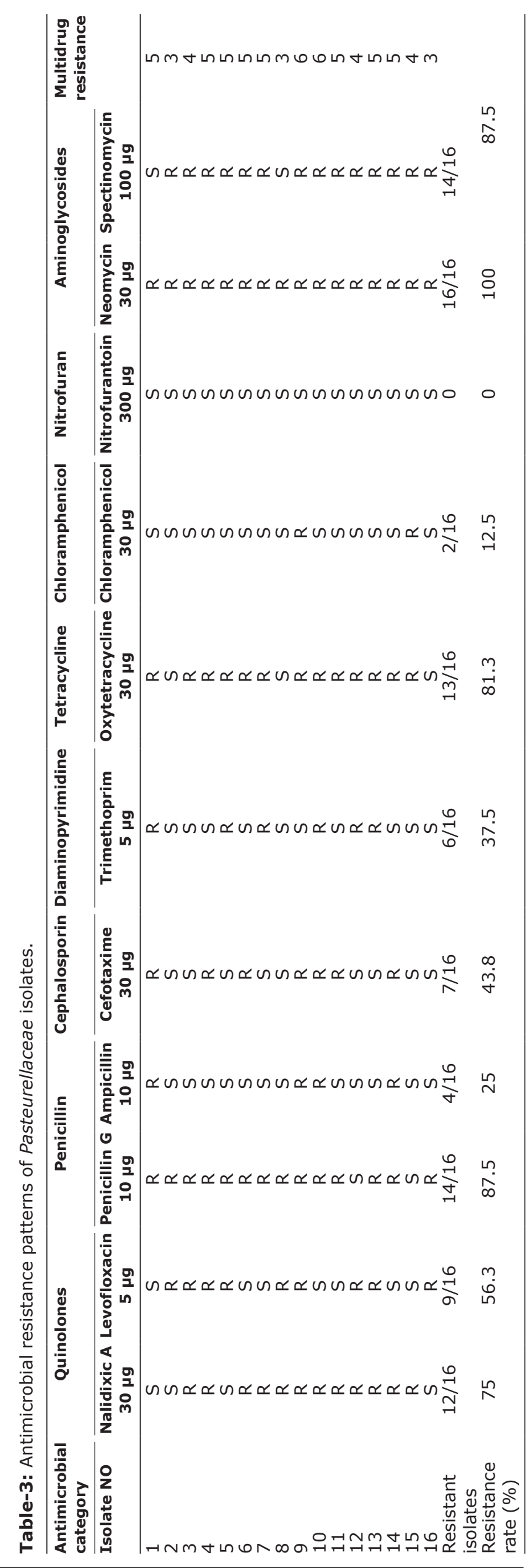

Veterinary World, EISSN: 2231-0916 

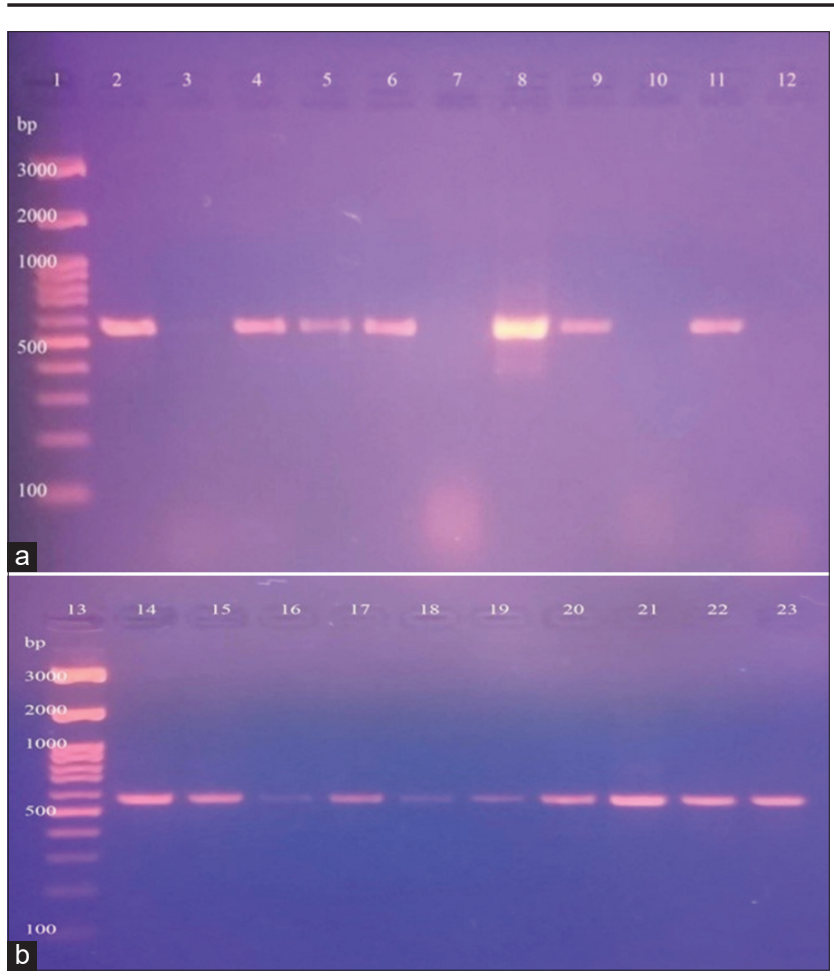

Figure-1: ( $a$ and $b$ ) lanes 1,13: Gel pilot 100 bp plus ladder, lane 23: positive control, lanes 2,4,5,6,8,9,11,14-22: positive specific amplicon for $P R p o b-\mathrm{L}$ gene at $560 \mathrm{bp}$, lanes $3,7,10$ : negative with no amplicon, lane 12: negative control.

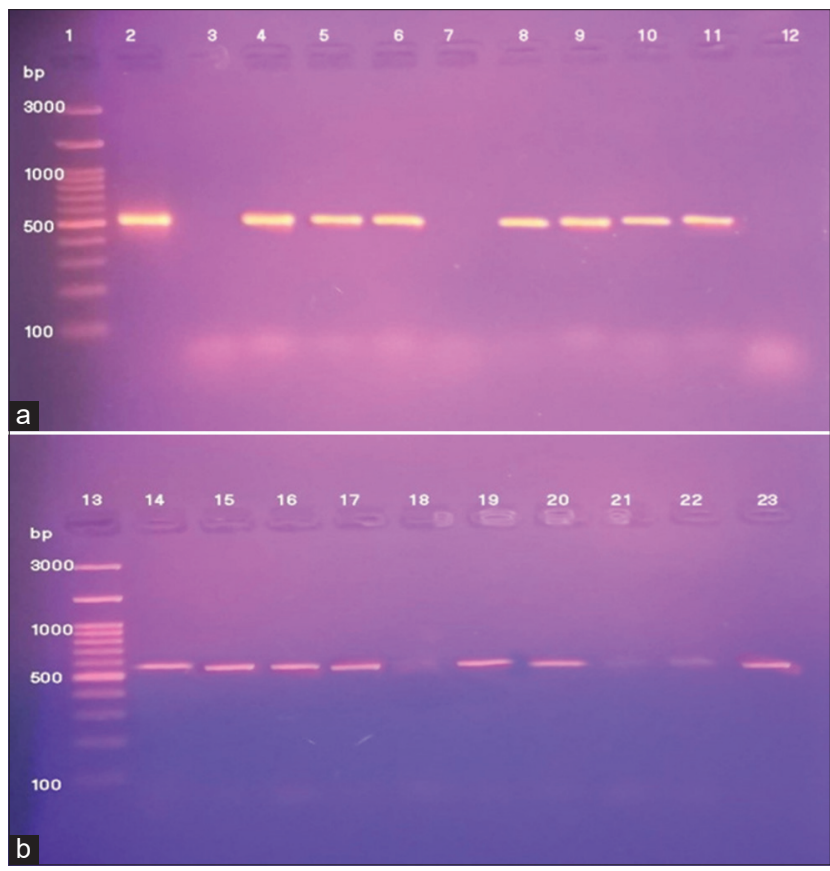

Figure-2: ( $a$ and $b$ ) lanes 1,13: Gel pilot 100 bp plus ladder, lane 23: positive control, lanes $2,4,5,6,8,9,10,11,14-17$, 19-22: positive amplicon, lanes 3,7,18: negative with no amplicon, lane 12: negative control.

as Pasteurella pneumotropica. Moreover, API $20 \mathrm{E}$ failed to identify $4 / 16$ (25\%) of Pasteurellaceae family members involved in the study.

\section{Discussion}

Pasteurellaceae family involves many pathogenic and non-pathogenic species. Meanwhile, several species are considered opportunistic secondary invaders that cause infections under predisposing circumstances; other species can play the role of primary pathogens that are capable of causing severe diseases in many animals [23]. In this regard, fowl cholera caused by P. multocida is considered the most important infectious diseases in birds, especially waterfowls [24].

In the present study, conventional bacteriological and biochemical methods were used to examine 112 freshly dead ducks with a history of respiratory manifestations and postmortem gross lesions for Pasteurellaceae infection, the results revealed the isolation of Pasteurellaceae from 16 out of 112 examined ducks with a prevalence rate of $14.3 \%$. Many studies accounted for conventional bacteriological methods and microscopic examination for demonstration of Gram-negative coccobacilli with a bipolar morphological appearance using Gram stain and Leishman's stain for the identification of $P$. multocida [25,26].

The results revealed that the highest prevalence of Pasteurella infection was observed in young ducklings of $<6$ weeks old as eight out of $28(28.6 \%)$ examined birds were positive for Pasteurella isolation, the results also revealed that two out of 16 Pasteurella isolates were identified by PCR as P. multocida and were isolated from the same age group. Moreover, 13 out of $16(81.25 \%)$ ducklings of $<12$ weeks old were positive to Pasteurella infection. These results were in agreement with the published scientific conclusions that birds younger than 11 weeks old were more prone to Pasteurella infection and that susceptibility of ducks most likely peaks somewhere between 4 and 11 weeks of the bird's age $[27,28]$.

Studying the association of breeds' susceptibility indicated that Muscovy breed encountered more infection compared to Mallard breed with prevalence rates of 6/39 (15.4\%), 10/73 (13.7\%), respectively. Similar studies recorded that Muscovy ducklings were found more susceptible to $P$. multocida infection compared to Pekin ducklings [29]. In the same regard, researches attributed the difference in immune response observed among different breeds of ducks to the breeds' response toward environmental stressors as excitement, injury, climate changes, and nutrition [24].

P. multocida is considered as the causative agent of fowl cholera, the infectious disease of major economic significance for several animal species worldwide. This bacterial agent is also known to infect over 100 species of wild birds and causes recurrent epizootics that can kill tens of thousands of birds in a single event, with little warning [30]. Meanwhile, most of the published surveillance that approached respiratory diseases in ducks focused primarily on detecting P. multocida and M. haemolytica, the studies were not informative for investigating and managing other family members implicated as causative agents in respiratory diseases. 
The current study targeted the identification of Pasteurellaceae members isolated from freshly dead ducks with a history of respiratory manifestation to the genus and species level using the available laboratory diagnostic tools.

The results revealed that the prevalence rates of Pasteurellaceae family members and $P$. multocida were $(14.3 \%)$ and $(1.7 \%)$, respectively. Higher prevalence rates for P. multocida (10.4\% and $25.2 \%$ ) from apparently healthy and diseased ducks were reported by other scientific studies, which concluded that P. multocida is the most predominant microorganism isolated from apparently healthy and diseased ducks followed by E. coli and staphylococci [9].

The results of the current study revealed that in addition to $P$. multocida other members of Pasteurellaceae family were implicated as causative agents in the investigated cases of respiratory manifestations and that $P$. multocida was not the prevailed isolated species. This result was confirmed by biochemical characterization and by PCR. Moreover, the pathogenicity of 16/16 Pasteurellaceae isolates was confirmed by applying bioassay in mice as an approved approach to test their pathogenicity [31]. Bioassay resulted in death of $32 / 32(100 \%)$ of I/P injected mice. Pathogenicity of non P. multocida isolates was attributed to the ability of normal commensal bacteria to encounter pathogenicity concordant with some changes in the host status [32].

PCR is a test that can be used for the identification of organisms at any level; strain, species, genus or members of a domain just by using specific primer sequence. Moreover, PCR was considered the most promising approach for detecting infection with Pasteurellaceae [33,34]. In the present study, PCR was used to confirm the results of conventional bacteriological isolation and biochemical characterization. PCR targeted the detection of Pasteurellaceae family specific conserved genes $R p o \mathrm{~B}$ gene (Beta-subunit of DNA-dependent RNA-polymerase) and Bootz R gene, the results confirmed that 16 out of $16(100 \%)$ isolates belonged to Pasteurellaceae family and produced the specific PCR products at 560-bp and at 533-bp, respectively. These results were in accordance with the scientific recommendation for the use of $R p o \mathrm{~B}$ gene for precise diagnosis, particularly in cases where phenotypic identification is difficult [35]. Moreover, the presence of phenotypic Pasteurellaceae variants makes it impossible to be correctly identified even by applying extended phenotypic characterization. Accordingly, the application of $16 \mathrm{~S}$ rDNA gene sequencing was proposed to allow the correct identification of such variants [5].

Meanwhile, PCR identified two out of 16 isolates $(12.5 \%)$ as $P$. multocida, attempts to identify the rest of 14 isolated Pasteurellaceae members to the genus and species level using PCR did not reveal the detection of A. paragallinarum (formerly Haemophilus paragallinarum) [36], $R$. anatipestifer, or M. haemolytica (formerly Pasteurella haemolytica). On the other hand,
PCR successfully identified five out of $16(31.3 \%)$ isolates as G. anatis. In this regard, growing demands were raised to apply more studies about $G$. anatis and its poorly understood growth kinetics, exact host-pathogen interplay, pathogenesis, and the switch from a normal inhabitant of healthy bird to a pathogen causing disease and mortality, virulence factors under more biologically relevant circumstances, and vaccines' production $[37,38]$.

Studies referred to the failure to isolate $M$. haemolytica to the higher concentration of iron required for its growth, the fastidious nature, the mesophilic nature, and the atmospheric requirements for facultative anaerobes and microaerophiles [6].

$R$. anatipestifer infection in ducklings produces a contagious disease, known as new duck disease or riemerellosis, during earlier periods it was misidentified as P. multocida due to their morphological and cultural similarities [39]. Trials were made by many researchers to isolate and identify $R$. anatipestifer as an important disease agent causing severe economic losses in ducks' industry. Similar to the current result some researches failed to detect $R$. anatipestifer [40]. In the same instance, other studies confronted difficulties with $R$. anatipestifer identification [41]. Furthermore, and with regard to the failure to detect $R$. anatipestifer in the current study conducted in Winter 2018 , other studies reported low incidence of $R$. anatipestifer in Winter in contrast to the high incidence of $R$. anatipestifer observed mainly during summer season with limited maximum morbidity and mortality rates in the period elapses from June to July and at the age group of 8-10 weeks old [42].

API 20E kit set was applied as a trial to identify the nine out of 16 isolates that could not be identified by the available PCR sets of primers. In this instance, API 20E system successfully identified 5/16 (31.3\%) as $P$. pneumotropica while failed to identify four isolates among the isolated Pasteurellaceae.

The identification of Pasteurellaceae to the species level by API 20E system solely is somehow unreliable due to the existence of taxa that are not included in the API database and due to the limited diagnostic agreement between laboratories studying the same strains [43], this conclusion supported the current finding as the applied API 20E set demonstrated limitations in the identification of all the tested isolates and successfully identified only 5/9 tested isolates (P. pneumotropica) while failed to biotype 4/9 isolates. Although some studies considered P. multocida and $P$. pneumotropica of greater pathogenic importance than other Pasteurellaceae, other studies considered this conclusion unjustified [44].

Many reports signified the importance of precise differentiation between Pasteurellaceae members to avoid excess considerable expenses caused by false or delayed diagnosis and to allow precise and rapid identification especially in case of infection by $R$. anatipestifer thus, mistaking it for $P$. 
multocida lead to exaggerated untrue consternation of fowl cholera, while confounding it with nonpathogenic Pasteurellaceae results in delayed diagnosis of Anatipestifer syndrome [45].

Reviewing the scientific study concerned with the isolation and identification of Pasteurellaceae members referred these common diagnostic problems mainly to poor growth nature of this family members on artificial media and to subsequent overgrowth by other bacterial species even before identification can be initiated, the scientific studies also referred to the difficulties represented by phenotypic differentiation and identification, and the lack of reliable commercial identification system.

In the current study, phenotypic antimicrobial resistance profiles of Pasteurellaceae isolates were investigated against 11 antimicrobial agents that belong to eight antimicrobial categories, and the results revealed that $16 / 16(100 \%)$ of studied isolates demonstrated phenotypic MDR attributes against three and more antimicrobial groups. The results also demonstrated that $100 \%$ of isolates demonstrated resistance against neomycin, while all 16/16(100\%) isolates were susceptible to nitrofurantoin. Moreover, 14/16 (87.5\%) of isolates demonstrated phenotypic resistance to spectinomycin and penicillin G, 13/16 (81.3\%) of isolates demonstrated phenotypic resistance to oxytetracycline, 12/16 (75\%) of isolates demonstrated resistance to nalidixic acid, and 9/16 (56.3\%) to levofloxacin. Moreover, resistance rates to cefotaxime, tetracycline, ampicillin, and chloramphenicol were 7/16 (43.8\%), $6 / 16(37.5 \%), 4 / 16(25 \%)$, and $2 / 16(12.5 \%)$, respectively. The MDR phenotypes observed among isolates may be attributed to the misuse of antimicrobial agents at the domestic field level. This finding accorded with reports published on the emergence of antimicrobial resistance among several organisms belonging to Pasteurellaceae family including $G$. anatis isolates [46].

Although nitrofuran is effective antimicrobial agent, its use in food animals was banned in the EU since 1995 as considered of carcinogenic effect $[47,48]$. Investigation on the resistance profiles of the circulating Pasteurellaceae members to nitrofurantoin was conducted by the current study and fortunately the results revealed the sensitivity of $16 / 16(100 \%)$ of the tested isolates, thus can be considered indicative to compliance of field stakeholders (farm owners and veterinarians) to restrictions applied on the field use of this banned dangerous antimicrobial agent.

In contrast to the resistance phenotypes observed among Pasteurellaceae isolates in the current study, susceptibility of avian $P$. multocida to chloramphenicol, gentamycin, tetracycline, penicillin G, streptomycin, sulfonamide, and trimethoprim were recorded by other studies [49]. In the same regard, an Egyptian study recorded that enrofloxacin, norfloxacin, and ciprofloxacin were the most effective antibiotics against P. multocida isolated from ducks [9]. Moreover, lower resistance rates of $P$. multocida to ampicillin, cephalothin $(<5 \%)$, and tetracycline $(6.2 \%)$ were recorded [50].

In accordance with the current results, resistance rates of $P$. multocida isolated from ducks to penicillin G (100\%), ampicillin (55\%), and tetracycline (10\%) were recorded [51]. Furthermore, some studies recorded phenotypic resistance of avian $P$. multocida isolates to enrofloxacin $(23.21 \%)$ and to sulfaquinoxaline $(76.79 \%)$, in addition to the observed multi-resistance in (19.64\%) of isolates [52].

Recent study also reported high resistance rates demonstrated by $G$. anatis isolated from chickens and turkeys to sulfadimethoxine $(93.3 \%)$, spectinomycin (93.3\%), and oxytetracycline (80.0\%), respectively [53]. Concerns were raised on the widespread MDR and substantial antigenic variation among strains of $G$. anatis as a major challenge that hinder treatment with antimicrobials $[54,55]$.

\section{Conclusion}

The study declared that laboratory diagnosis by conventional bacteriological and biochemical methods for the identification and differentiation between Pasteurellaceae family members was not sufficient for reliable genus and species identification, and discrimination. Thus, it signified the importance of applying combined bacteriological, biochemical, genetic, and virulence studies for the differentiation between Pasteurellaceae family members to provide clear epidemiological data that contribute in the effective control of pasteurellosis. Moreover, it is recommended to apply targeted survey on Pasteurellaceae in ducks' production sector and investigate the resistance and virulence circulating profiles for the provision of valuable insights into respiratory problems and apply effective control measures in ducks' farms in Egypt.

\section{Authors' Contributions}

SE designed the study, applied bacteriological examinations, Wrote and revised the manuscript and manage correspondence. SM applied PCR testing. HYH collected the samples and applied postmortem examinations. NMA applied bacteriological examinations and wrote the manuscript. All authors read and approved the final manuscript.

\section{Acknowledgments}

Thanks are presented to our colleagues Yousreya Hashem, the researcher in Biotechnology Department, AHRI, Egypt and Fatma Amer the researcher in Biotechnology Department, RLQP, AHRI, Egypt for their technical support. The study was conducted with resources of Reference Laboratory for Veterinary Quality Control on Poultry Production, Dokki, Egypt. The authors did not receive any fund for this study.

\section{Competing Interests}

The authors declare that they have no competing interests. 


\section{Publisher's Note}

Veterinary World remains neutral with regard to jurisdictional claims in published institutional affiliation.

\section{References}

1. Adzitey, F. and Adzitey, S.P. (2011) Duck production has the potential to reduce poverty among rural households in Asian communities a review. J. Worlds Poult. Res., 1(1): 7-10.

2. Food and Agriculture Organization of the United Nations. (2017) Food and Agriculture Organization of the United Nations' Database. Available from: http://www.fao. org/statistics/en.Last accessed on 16-12-2019.

3. Cheng, L.I.Z., Cheng, F., Shimei, L.A.N., Jianhua, G.U.O., Wei, L.I.U., Oyan, L.I.X., Zeli, L.U.O., Zhang, M., Juan, W.U. and Yang, S.H.I. (2018) Investigation of genetic diversity and epidemiological characteristics of Pasteurella multocida isolates from poultry in southwest China by population structure, multi-locus sequence typing and virulence-associated gene profile analysis. J. Vet. Med. Sci., 80(6): 921-929.

4. Korczak, B., Christensen, H., Emler, S., Frey, J. and Kuhnert, P. (2004) Phylogeny of the family Pasteurellaceae based on RpoB sequences. Int. J. Syst. Evol. Microbiol., 54(4): 1393-1399.

5. Christensen, H., Bisgaard, M., Bojesen, A., Mutters, R. and Olsen, J. (2003) Genetic relationships among avian isolates classified as Pasteurella haemolytica, "Actinobacilluss alpingitidis" or Pasteurella anatis with proposal of Gallibacterium anatis and description of additional genomo species within Gallibacterium gen. Nov. Int. J. Syst. Evol. Microbiol., 53(1): 275-287.

6. Angen, Ø., Mutters, R., Caugant, D.A., Olsen, J.E. and Bisgaard, M. (1999) Taxonomic relationships of Pasteurella haemolytica complex as evaluation by DNA-DNA hybridizations and 16S RNA sequencing with proposal of Manheima haemolytica gen. Nov., comb. nov., Manheima granulomatis comb. nov., Manheima glucosida sp. Nov., sp. Nov., Manheima varigena sp. Nov. Int. J. Syst. Bacteriol., 49(1): 67-86.

7. Wahyuni, A.E.T., Tabbu, C.R., Artanto, S., Setiawan, D.C.B. and Rajaguguk, S.I. (2018) Isolation, identification, and serotyping of Avibacterium paragallinarum from quails in Indonesia with typical infectious coryza disease symptoms. Vet. World, 11(4): 519-524.

8. Bisgaard, M. (1982) Isolation and characterization of some previously unreported taxa from poultry with phenotypic characters related to Actinobacillus and Pasteurella species. Acta Pathol. Microbiol. Immunol. Scand. B, 90(1): 59-67.

9. Eid, H.M., Algammal, A.M., Elfeil, W.K., Youssef, F.M., Harb, S.M. and Abd-Allah, E.M. (2019) Prevalence, molecular typing, and antimicrobial resistance of bacterial pathogens isolated from ducks. Vet. World, 12(5): 677-683.

10. Abbas, A.M., Abd El-Moaty, D.A.M., Zaki, E.S.A., El-Sergany, E.F., El-Sebay, N.A., Fadl, H.A. and Samy, A.A. (2018) Use of molecular biology tools for rapid identification and characterization of Pasteurella spp. Vet. World, 11(7): 1006-1014.

11. OIE, Terrestrial Animal Health Code. (2018) Introduction to the Recommendations for Animal Welfare. Ch. 7.1. Terrestrial Animal Health Code-10/09/2018. OIE, Terrestrial Animal Health Code, Paris, France.

12. Florence, D., Thomann, A., Brodard, I., Korczak, B.M., Schlatter, Y., Kuhnert, P., Miserez, R. and Frey, J. (2008) Routine phenotypic identification of bacterial species of the family Pasteurellaceae isolated from animals. J. Vet. Diagn. Invest., 20(6): 716-724

13. Bisgaard, M., Houghton, S.B., Mutters, R. and Stenzel, A. (1991) Reclassification of German, British and Dutch isolates of so-called Pasteurella multocida obtained from pneumonic calf lungs. Vet. Microbiol., 26(1-2): 115-124.

14. Ramdani, R.R., Dawkins, H.J., Johnson, R.B., Spencer, T.L. and Adler, B. (1990) Pasteurella multocida infections in mice with reference to hemorrhagic septicemia in cattle and buffalo. Immunol. Cell Biol., 68(1): 57-61.

15. CLSI, Clinical and Laboratory Standards Institute. (2015) M02-A12 Performance Standards for Antimicrobial Disk Susceptibility Tests; Approved Standard. 12 th $^{\text {th }}$ ed. CLSI Document, Wayne. Clinical and Laboratory Standards Institute. (2010) M45 A2: Methods for Antimicrobial Dilution and Disk Susceptibility Testing of Infrequently Isolated or Fastidious Bacteria, Approved Guideline. $2^{\text {nd }} \mathrm{ed}$. Clinical and Laboratory Standards Institute, Wayne.

16. Bootz, F., Kirschnek, S., Nicklas, W., Wyss, S.K. and Homberger, F.R. (1998) Detection of Pasteurellaceae in rodents by polymerase chain reaction analysis. Lab. Anim. Sci., 48(5): 542-546.

17. Tsai, H.J., Liu, Y.T., Tseng, C.S. and Pan, M.J. (2005) Genetic variation of the OMP A and 16S rRNA gene of Riemerella anatipestifer. Avian Pathol., 34(1): 55-64.

18. Shancy, C., Priya, P.M., Sabnam, V.S., Syam, R. and Mini, M. (2018) Rapid detection of Riemerella anatipestifer isolates using 16S rRNA based PCR and species-specific PCR assay. Int. J. Sci. Environ. Technol., 7(5): 1802-1812.

19. Bojesen, A.M., Christensen, J.P. and Bisgaard, M. (2008) Gallibacterium infections and other avian Pasteurellaceae. In: Pattison, M., McMullin, P.F., Bradbury, J.M. and Alexander, D.I., editors. Poultry Diseases. $6^{\text {th }}$ ed. Saunders Elsevier, Philadelphia, PA. p160-163.

20. Deressa, A., Asfaw, Y., Lubke, B., Kyule, M.W., Tefera, G. and Zessin, K.H. (2010) Molecular detection of Pasteurella multocida and Mannheimia haemolytica in sheep respiratory infections in Ethiopia. Int. J. Appl. Res. Vet. Med., 8(2): 101-108.

21. Townsend, K.M., Boyce, J.D., Chung, J.Y., Frost, A.J. and Adler, B. (2001) Genetic organization of Pasteurella multocida cap Loci and development of a multiplex capsular PCR typing system. J. Clin. Microbiol., 39(3): 924-929.

22. Patil, V.V., Mishra, D. and Mane, D.V. (2017) 16S ribosomal RNA sequencing and molecular serotyping of Avibacterium paragallinarum isolated from Indian field conditions. Vet. World, 10(8): 1004-1007.

23. Olsen, I., Dewhirst, F.E., Paster, B.J. and Busse, H.J. (2005) Pasteurellaceae. In: Brenner, D.J., Krieg, N.R. and Staley, J.T., editors. Bergey's Manual of Systematic Bacteriology. Vol. 2. Springer, New York. p851-912.

24. Liu, R.C., Chen, C., Cheng, L.F., Lu, R.H., Fu, G.H., Shi, S.H., Chen, H.M., Wan, C., Lin, J.S., Ling, F.Q. and Huang, Y. (2017) Ducks as a potential reservoir for Pasteurella multocida infection detected using a new rOmpH-based ELISA. J. Vet. Med. Sci., 79(7): 1264-1271.

25. Akhtar, M. (2013) Isolation, Identification and Characterization of Pasteurella multocida from Chicken and Development of Oil Based Vaccine, MS Thesis, Department of Microbiology and Hygiene. Bangladesh Agricultural University, Mymensingh.

26. Ponnusamy, P., Reetha, T.L., Ronald, B.S.M., Puvarajan, B. and Manickam, R. (2018) Molecular detection and characterization of Pasteurella multocida from migratory ducks in the Cauvery delta region of Tamil Nadu. J. Entomol. Zool. Stud., 6(2): 2273-2276.

27. Hunter, B. and Wobeser, W. (1980) Pathology of experimental avian cholera in Mulard ducks. Avian Dis., 24(2): 403-414.

28. Mbuthia, P.G., Njagi, L.W., Nyaga, P.N., Bebora, L.C., Minga, U., Kamundia, J. and Olsen, J.E. (2008) Pasteurella multocida in scavenging family chickens and ducks: Carrier status, age susceptibility and transmission between species. Avian Pathol., 37(1): 51-57.

29. Afifi, S.I. and El-Nesr, K.A. (2013) Bacteriological, pathological and immunohistochemical studies on Pasteurella 
spp. isolated from ducks in Benisuef governorate. Egypt. J. Comp. Pathol. Clin. Pathol., 26(1): 28-48.

30. Jaeger, A., Lebarbenchon, C., Bourret, V., Bastien, M., Lagadec, E. and Thiebot, J.B. (2018) Avian cholera outbreaks threaten seabird species on Amsterdam Island. PLoS One, 13(5): e0197291.

31. Mohamed, M., Abd Al-Azeem, M.W., Ibrahim, A.I. and Ahmed, M.S. (2012) Pasteurella multocida in backyard chickens in Upper Egypt: Incidence with polymerase chain reaction analysis for capsule type, virulence in chicken embryos and antimicrobial resistance. Vet. Ital., 48(1): 77-86.

32. Paudel, S., Alispahic, M., Liebhart, D., Hess, M. and Hess, C. (2013) Assessing pathogenicity of Gallibacterium anatis in a natural infection model: The respiratory and reproductive tracts of chickens are targets for bacterial colonization. Avian Pathol., 42(6): 527-535.

33. Bhimani, M.P., Roy, A., Bhanderi, B.B. and Mathakiya, R.A. (2014) Isolation, identification and molecular characterization of Pasteurella multocida isolates obtained from emu in Gujarat state, India. Vet. Arhiv, 84(4): 411-419.

34. Aguiarribeiro, T.S. (2011) Detection of Pasteurellaceae in Laboratory Mice by Fecal PCR. Thesis Presented to Escola Superior de Biotecnologia of the Universidad de Católica Portuguesa to Fulfill the Requirements of Master of Science Degree in Microbiology.

35. Christensen, H., Kuhnert, P., Busse, H., Frederiksen, W. and Bisgaard, M. (2007) Proposed minimal standards for the description of genera, species and subspecies of the Pasteurellaceae. Int. J. Syst. Evol. Microbiol., 57(1): 166-178.

36. Somu, C., Radhakrishnan, U. and Pala, S. (2016) Outer membrane protein a gene-based diagnosis of Riemerella anatipestifer infections in ducks. Adv. Vet. Anim. Sci., 4(10): 527-535.

37. Singh, S.V., Singh, B.R., Sinha, D.K., Kumar, V.O.R., Vadhana, P.A., Bhardwaj, M. and Dubey, S. (2016) Gallibacterium anatis: An emerging pathogen of poultry birds and domiciled birds. J. Vet. Sci. Technol. 7: 324.

38. Persson, G. and Bojesen, A.M. (2015) Bacterial determinants of importance in the virulence of Gallibacterium anatis in poultry. Vet. Res., 46(1): 57.

39. Surya, P.S., Priya, P.M. and Mini, M. (2016) Protein profiling and restriction enzyme analysis of Riemerella anatipestifer from ducks in Kerala. Indian J. Poult. Sci., 51(2): 151-154.

40. Hinz, K.H., Ryll, M., Kohler, B. and Glunder, G. (1998) Phenotypic characteristics of Riemerella anatipestifer and similar micro-organisms from various hosts. Avian Pathol., 27(1): 33-42.

41. Rubbenstroth, D., Ryll, M., Knobloch, J.K.M., Köhler, B. and Rautenschlein, S. (2013) Evaluation of different diagnostic tools for the detection and identification of Riemerella anatipestifer. Avian Pathol., 42(1): 17-26.

42. Haque, A.F.M. (1987) A study on duck pasteurellosis with a special emphasis on a Pasteurella anatipestifer infection. MS Thesis, Department of Medicine. Bangladesh Agricultural University, Mymensingh, Bangladesh.

43. Boot, R., Van den Brink, M., Handgraaf, P. and
Timmermans, R. (2004) The use of the API 20 NE bacteria classification procedure to identify Pasteurellaceae strains in rodents and rabbits. Scand. J. Lab. Anim. Sci., 3(31): 177-183.

44. Boot, R. (1997) Microbiological quality assurance of laboratory animals exemplified by the family Pasteurellaceae. In: O'Donoghueed, P.N., editor. Harmonization of Laboratory Animal Husbandry. The Royal Society of Medicine Press, London. p59-63.

45. Kardos, G., Nagy, J., Anta, M., Bistya'k, A., Tenk, M. and Kiss, I. (2007) Development of a novel PCR assay specific for Riemerella anatipestifer. Lett. Appl. Microbiol., 44(2): 145-148.

46. Aarestrup, F.M. (2005) Veterinary drug usage and antimicrobial resistance in bacteria of animal origin. Basic Clin. Pharmacol. Toxicol., 96(4): 271-281.

47. EC, European Commission. (2003) Regulation 2901/93/EEC of the council of 18 October 1993 on amending annexes I, II, III and IV to regulation (EEC) No. 2377/90 laying down a community procedure for the establishment of maximum residue limits of veterinary medicinal products in foodstuffs of animal origin. Official J. L., 264: 1-4.

48. Jiang, W., Luo, P., Wang, X., Chen, X. and Zhao, Y. (2012) Development of an enzyme-linked immunosorbent assay for the detection of nitrofurantoin metabolite, 1-amino-hydantoin, in animal tissues. Food Control, 23(1): 20-25.

49. Hirsh, D.C., Hansen, L.M., Dorfman, L.C., Snipes, K.P., Carpenter, T.E., Hird, D.W. and McCapes, R.H. (1989) Resistance to antimicrobial agents and prevalence of R plasmids in Pasteurella multocida from Turkeys. Antimicrob. Agents Chemother., 33(5): 670-673.

50. Huang, T.M., Lin, T.L. and Wu, C.C. (2009) Antimicrobial susceptibility and resistance of chicken Escherichia coli, Salmonella spp., and Pasteurella multocida isolates. Avian Dis., 53(1): 89-93.

51. Kamruzzama, M., Islam, M., Hossain, M.M., Hassan, M.K., Kabir, M.H.B., Sabrin, M.S. and Khan, M.S.R. (2016) Isolation, characterization and antibiogram study of Pasteurella multocida isolated from ducks of Kishoreganj district, Bangladesh. Int. J. Anim. Resour., 1(1): 69-76.

52. Furian, T.Q., Borges, K.A., Laviniki, V., da Silveira Rocha, S.L., de Almeida, C.N., do Nascimento, V.P., Salle, C.T. and de Souza Moraes, H.L. (2016) Virulence genes and antimicrobial resistance of Pasteurella multocida isolated from poultry and swine. Braz. J. Microbiol., 47(1): 210-216.

53. Hosny, E., Bocklisch, H., Neubauer, H., Hafez, H.M. and Hotze, H. (2018) Identification, differentiation and antibiotic susceptibility of Gallibacterium isolates from diseased poultry. Ir. Vet. J., 71: 5.

54. Paudel, S., Hess, M. and Hess, C. (2017) Coinfection of Avibacterium paragallinarum and Gallibacterium anatis in specific-pathogen-free chickens complicates clinical signs of infectious coryza, which can be prevented by vaccination. Avian Dis., 61(1): 55-63.

55. Persson, G., Pors, S.E., Thøfner, I.C.N. and Bojesen, A.M. (2018) Vaccination with outer membrane vesicles and the fimbrial protein FlfA offers improved protection against lesions following challenge with Gallibacterium anatis. Vet. Microbiol., 217(April): 104-111. 